\title{
Wahana Edukasi Profesi Anak Di Surakarta Dengan Pendekatan ArsitekTUR Perilaku
}

\author{
Bagas Prihandhana, Musyawaroh, Tri Joko Daryanto \\ Program Studi Arsitektur \\ Universitas Sebelas Maret Surakarta \\ Email : prihandhanabagas@gmail.com
}

\begin{abstract}
Nowadays most children tend to take advantage of playing time with activities that could potentially have a negative impact. Specifically, children who live in the urban areas commonly spend their time playing games, computers, internet, etc. From some games mode that already exist, one method is role playing. In the education of the profession that well planned, this method provides a positive impact for children, which can embed a sense of the role of the profession in life, embed the responsibility to cooperate with others, respect other people's opinions and abilities, and learn to make decisions in a relations group. Behavioral architecture approach required in the design of educational professions facilities for children. By applying the behavioral architecture approach, it's expected to create a space and a certain ambiance in accordance with the child's behavior and their environment. So, the behavior of the children will affected the design of the building, so that the child's behavior and character will be used as a basic reference in the design of the building. So conversely, the design of the building is expected to give a positive impact on children's behavior.
\end{abstract}

Keywords : Behavior, Children, Education, Facilities, Profession

\section{PENDAHULUAN}

Dewasa ini kebanyakan anak-anak cenderung memanfaatkan waktu bermain dengan kegiatan yang berpotensi menimbulkan dampak negatif. Secara khusus, anak-anak yang tinggal di daerah perkotaan umumnya menghabiskan waktu bermain mereka dengan game, komputer, internet, dan lain sebagainya. Hal tersebut memang memberikan dampak positif, akan tetapi yang perlu diperhatikan adalah dampak negatifnya. Permainan modern produk teknologi menjadi disukai di kalangan anak-anak karena kaya sensasi dan penuh fantasi. Permainan modern produk teknologi menjadi semakin praktis, karena tidak memerlukan lahan yang lapang dan banyak teman. Namun, permainan modern produk teknologi tidak sepenuhnya memberi pengaruh baik bagi anak, kehadiran permainan modern produk teknologi yang semakin merambat, menimbulkan gejala yang dapat dilihat secara obyektif, misalnya perilaku anak yang menjadi lebih agresif, menjurus kekerasan, egois, tidak toleran dan lain sebagainya.
Memperhatikan kondisi tersebut, maka dibutuhkan metode bermain yang memberi dampak positif terhadap perilaku anak. Dari beberapa wahana permainan yang sudah ada, salah satu metode yang digunakan adalah metode role playing. Metode role playing atau disebut juga dengan istilah sosiodrama adalah permainan yang dilakukan oleh anak tentang satu situasi, dapat pula diartikan bermain peranan. Metode role playing diterapkan atas dasar pemilihan peranan profesi yang memiliki nilai-nilai moral. Pada pengenalan profesi yang direncanakan dengan baik, metode ini memberikan dampak positif bagi anak, antara lain dapat menanamkan pengertian peranan suatu profesi dalam kehidupan, menanamkan kemampuan bertanggung jawab dalam bekerja sama dengan orang lain, menghargai pendapat dan kemampuan orang lain, dan belajar mengambil keputusan dalam hubungan kerja kelompok.

Wahana yang berkonsep pada pengenalan profesi seperti ini juga sudah hadir 
di beberapa negara di dunia. Bahkan sejauh ini banyak negara yang tertarik membangun wahana dengan konsep serupa karena dinilai memiliki manfaat yang baik bagi anak-anak dan juga memiliki potensi yang besar bagi para investor. Pada umumnya di Indonesia sendiri, bangunan dengan konsep serupa baru terdapat di Kota Jakarta. Padahal wahana ini bermanfaat untuk mengenalkan dunia profesi bagi anak.

Di samping fenomena-fenomena tersebut, hal yang menguatkan bahwa bangunan wahana edukasi profesi anak perlu untuk dikembangkan di Kota Surakarta adalah sehubungan dengan upaya pemerintahan mewujudkan Kota Surakarta sebagai kota layak anak pada tahun 2008 hingga 2016.

Pendekatan Arsitektur Perilaku diperlukan dalam desain wahana edukasi profesi anak. Dengan menerapkan pendekatan Arsitektur Perilaku, diharapkan dapat menciptakan ruang dan suasana tertentu yang sesuai dengan perilaku anak beserta lingkungan. Perilaku dapat membentuk suatu lingkungan dan lingkungan dapat membentuk suatu perilaku. Perilaku anak-anak akan berpengaruh pada desain bangunan, sehingga perilaku dan karakter anak akan dijadikan dasar acuan dalam desain bangunan. Begitu juga sebaliknya, desain bangunan diharapkan dapat memberi dampak positif terhadap perilaku anak.

\section{METODE}

\subsection{Macam dan Teknik Pengumpulan Data}

1. Data Preseden : didapat melalui observasi, tinjauan langsung dan dokumentasi terhadap bangunan dengan fungsi yang sejenis. Data lain didapat dari situs resmi www.kidzania.co.id, serta dari beberapa artikel terkait.

2. Data Arsitektur Perilaku : didapat melalui referensi buku 'Arsitektur dari segi Perilaku' (Heimsath, Clovis) dan beberapa jurnal terkait.

3. Data Topografi : didapat melalui observasi dan dokumentasi rupa muka tanah, selain itu data juga didapat melalui data instansional pemkot serta melalui situs dan beberapa artikel terkait.
4. Data Peta Kependudukan dan Sosiografi : didapat melalui data instansional pemkot serta melalui situs dan beberapa artikel terkait.

5. Data Struktur : didapat dari mata kuliah mengenai sistem struktur serta beberapa situs dan buku referensi.

\subsection{Metode Analisis Data}

Analisis perencanaan (building concept) mengidentifikasi masalah yang ada berdasarkan konsep rancangan wahana edukasi profesi anak di Surakarta yang diselesaikan dengan pendekatan Arsitektur Perilaku.

Analisis perancangan (building criteria) dilakukan dengan mengolah data yang telah terkumpul dan dikelompokkan berdasarkan pemrograman fungsional, performasi, dan arsitektural.

1. Pemrograman fungsional bertujuan untuk mengidentifikasi penggunaan wahana edukasi profesi anak, di antaranya pelaku kegiatan, jenis kegiatan, kelompok kegiatan, pola kegiatan, sifat kegiatan

2. Pemrograman performansi menerjemahkan secara sistematik kebutuhan para pengguna wahana edukasi profesi anak beserta fasilitasnya ke dalam persyaratan pemilihan tapak, persyaratan kebutuhan ruang, persyaratan besaran ruang dan program ruang, serta penerapan Arsitektur Perilaku pada bangunan yang direncanakan.

3. Analisis arsitektural merupakan tahap penggabungan dari hasil identifikasi kedua analisa sebelumnya (fungsional dan performansi). Dalam proses ini akan menganalisa masalah massa, ruang bagian dalam, tampilan, pengolahan tapak, sistem utilitas, dan struktur bangunan.

\section{ANALISIS}

3.1 Analisis Pelaku dan Jenis Kegiatan

Tabel 1. Pelaku dan Jenis Kegiatan

\begin{tabular}{|c|l|l|}
\hline PELAKU & KEGIATAN & $\begin{array}{l}\text { JUMLAH } \\
\text { (ORANG) }\end{array}$ \\
\hline \hline Pengunjung & Datang & \multicolumn{1}{|l}{} \\
\cline { 2 - 3 } &
\end{tabular}




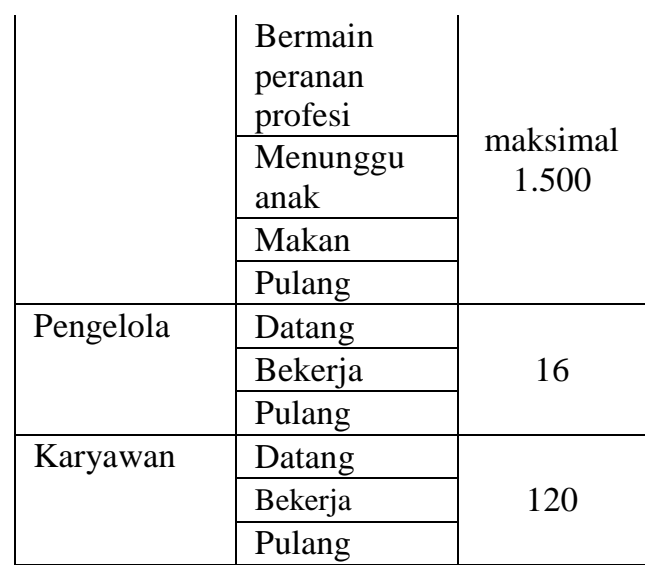

Pada Tabel 1. terlihat pengelompokan pelaku dan jenis kegiatan, serta jumlah pelaku kegiatan yang diwadahi dalam bangunan wahana edukasi profesi anak.

\subsection{Analisis Peruangan}

Tabel 2. Kebutuhan Ruang

\begin{tabular}{|l|l|}
\hline \multirow{2}{*}{ KEGIATAN } & \multicolumn{1}{|c|}{$\begin{array}{c}\text { KEBUTUHAN } \\
\text { RUANG }\end{array}$} \\
\hline \hline Penerimaan & Area parkir \\
\cline { 2 - 2 } & Hall \\
\hline $\begin{array}{l}\text { Peranan } \\
\text { profesi }\end{array}$ & $\begin{array}{l}\text { Arena bermain } \\
\text { peranan profesi }\end{array}$ \\
\hline Penunjang & $\begin{array}{l}\text { Ruang tunggu orang } \\
\text { tua }\end{array}$ \\
\cline { 2 - 2 } & Ruang konsultasi \\
\cline { 2 - 2 } & Foodcourt \\
\hline Komersil & Minimarket \\
\cline { 2 - 2 } & Toko cindera mata \\
\hline Pengelola & Ruang kantor \\
\hline Servis & Ruang karyawan \\
\cline { 2 - 2 } & Ruang Servis \\
\hline
\end{tabular}

Pada Tabel 2. terlihat kebutuhan peruangan sebagai pemenuhan berbagai wadah kegiatan di dalam bangunan.

\subsection{Analisis Lokasi}

Pemilihan lokasi dengan kondisi yang mendukung keberadaan bangunan akan menentukan prospek wahana edukasi profesi anak ke depan. Lokasi harus sesuai dengan peruntukan tata guna lahan sesuai dengan aturan dari pemerintah kota.
1. Tujuan : mendapatkan lokasi yang sesuai dengan peruntukan tata guna lahan.

2. Dasar pertimbangan : posisi tapak yang strategis untuk menonjolkan tampilan fisik bangunan, tidak terlalu jauh dari kawasan pendidikan/sekolah, dan mudah diakses baik menggunakan kendaraan umum maupun pribadi.

3. Proses analisis

a. Lokasi terpilih termasuk dalam SWP II Kota Surakarta yang memiliki fungsi sebagai daerah pariwisata, ruang terbuka hijau dan keuangan.

b. Agar akses menuju bangunan lebih mudah, maka dipilih lokasi yang diapit oleh dua sisi jalan.

\subsection{Analisis Pencapaian}

Pencapaian menuju ke dalam bangunan perlu dirancang agar mudah dicapai baik oleh kendaraan umum maupun pribadi, memiliki kelancaran sirkulasi, dan pintu masuk yang jelas.

1. Tujuan : menentukan main entrance dan side entrance

2. Dasar pertimbangan : kemudahan akses, sirkulasi yang mudah dipahami, arus kendaraan dan tingkat keamanan.

3. Proses analisis

Main Entrance (ME)

Mudah dijangkau dan terlihat dengan jelas. Digunakan untuk akses pengunjung. Menghadap langsung ke arah Jl. Adi Sucipto.

Side Entrance (SE)

Tidak mengganggu keberadaan ME. Digunakan untuk akses pengelola dan karyawan. Menghadap ke arah Jl. Siwalan. 


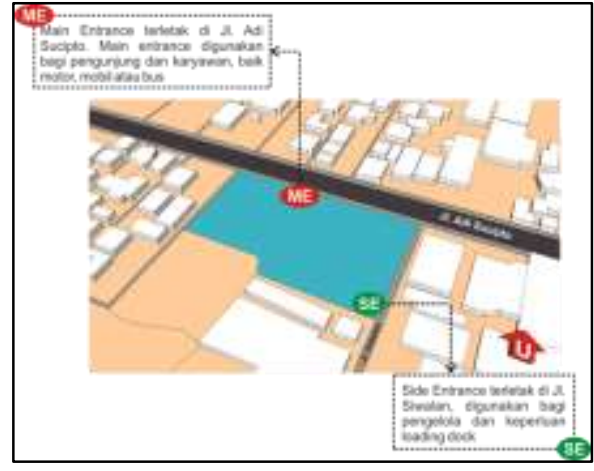

Gambar 1. Pola Pencapaian

\subsection{Analisis Pemintakatan (Penzoningan)}

Pemintakatan berdasarkan sifat kegiatan dan peruangan, serta keadaan dalam tapak dilakukan sebagai acuan dalam penataan peruangan.

1. Tujuan : menentukan mintakat (zoning) berdasarkan sifat kegiatan dan peruangan, serta keadaan dalam tapak.

2. Dasar pertimbangan : analisis peruangan, analisis pengolahan tapak, analisis sistem struktur.

3. Proses analisis : persyaratan ruang, berdasarkan kelompok kegiatan dan analisis pengolahan tapak.

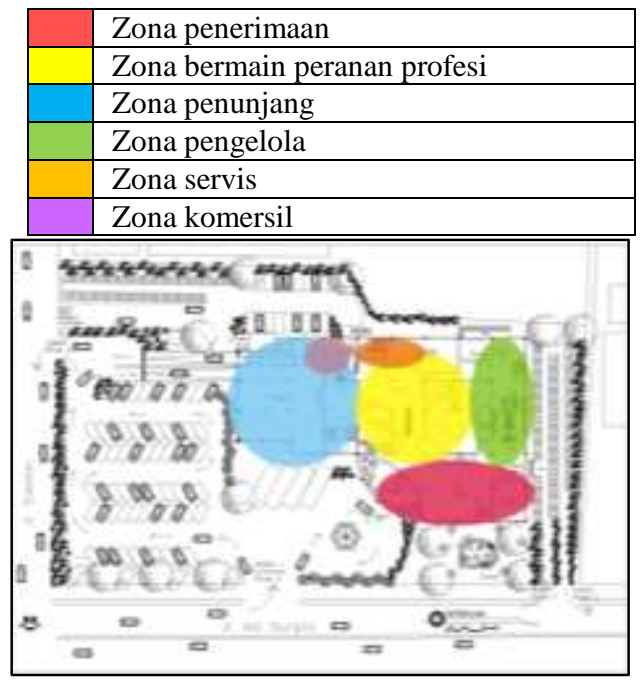

Gambar 2. Pola Pemintakatan

\subsection{Analisis Bentuk Fisik Bangunan}

1. Tujuan : mendapatkan desain bentuk dan fasad bangunan yang menarik dan dinamis.

2. Dasar pertimbangan : prinsip psikologi warna, bentuk bangunan yang dinamis, atraktif dan komunikatif.

3. Proses analisis

a. Bentuk dinamis diwujudkan dengan penerapan kolaborasi bentuk lengkung dengan diagonal,sehingga bangunan mudah dikenali dengan hanya melihat wujudnya.

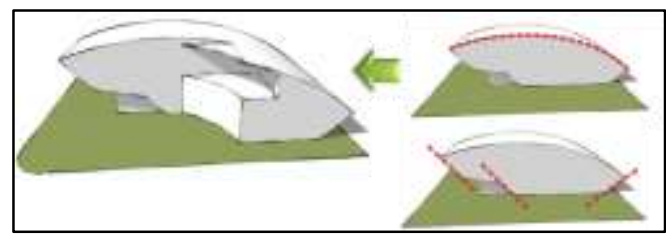

Gambar 3. Bentuk Bangunan

b. Bentuk atraktif diwujudkan dengan aksen pola batik berbentuk belah ketupat sebagai kaca dengan menggunakan warna pastel.
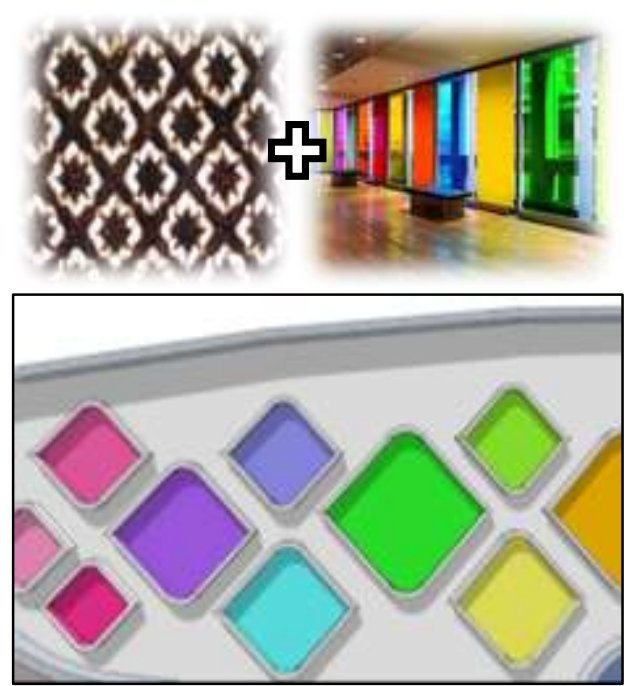

Gambar 4. Pola Batik pada Tampilan Bangunan

c. Bentuk komunikatif diwujudkan dengan menggunakan sculpture/patung berupa profesi tertentu yang diletakkan pada taman sebagai ikon wahana edukasi profesi anak. 


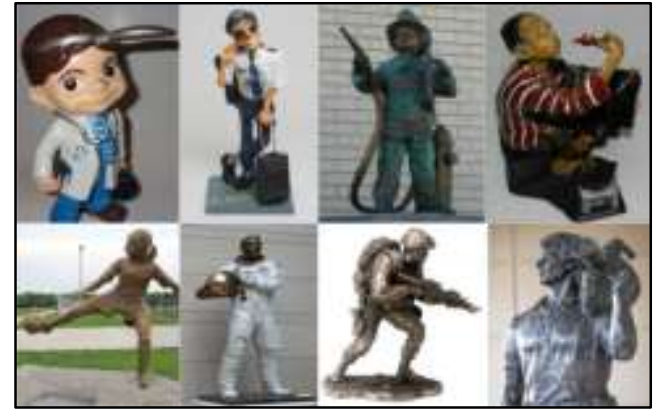

Gambar 5. Patung dengan Tema Profesi (sumber: www.rubylane.com)

\subsection{Analisis Interior Bangunan}

1. Tujuan : mendapatkan desain tata ruang dan bahan bangunan yang sesuai dengan karakteristik anak dengan pendekatan aspek perilaku.

2. Dasar pertimbangan : pola tata ruang, fleksibilitas ruang, jenis bahan yang digunakan untuk bagian lantai, dinding dan plafon.

3. Proses analisis : bagian pada dalam bangunan (interior) merupakan salah satu elemen penting dalam perancangan wahana edukasi profesi anak.

a. Tata peruangan salah satunya dengan desain split level untuk ruang yang sekiranya menutupi ruangan yang lainnya. Hal ini dilakukan untuk membatasi ruang tanpa mengurangi jarak pandang terhadap ruang yang lainnya.

b. Material yang digunakan pada lantai yaitu lantai karet (rubber flooring) dan vinyl motif kayu. Hal ini dikarenakan anak memiliki pergerakan yang aktif dan keamanan perlu diutamakan. Kedua material lantai tersebut tidak licin, sehingga mengurangi resiko anak terpeleset. Di samping itu, pola lantai pada koridor di zona bermain peranan profesi didesain agar anak lebih mudah menemukan ruang-ruang bermain, di samping itu juga untuk membedakan ruang yang tidak boleh diakses oleh anak.

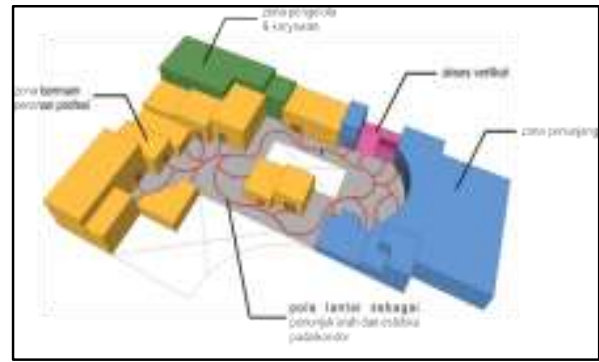

Gambar 6. Pola Lantai sebagai Penunjuk Arah

c. Material yang digunakan pada dinding luar yaitu bata merah, sedangkan untuk dalam ruangan menggunakan partisi dari papan kalsium. Karena sifatnya yang mudah dibongkar pasang, sehingga mengakomodasi tata ruang yang bebas dan tema ruang yang dapat diubah-ubah dalam kurun waktu tertentu.

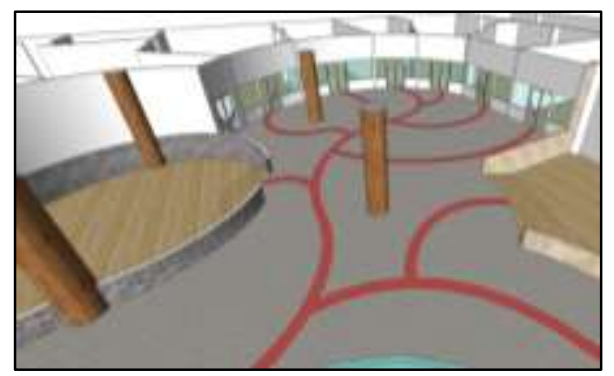

Gambar 7. Ruang Bagian Dalam Bangunan

d. Material yang digunakan pada plafon yaitu papan kalsium dengan tema cat warna langit yang berbeda pada setiap lantai bangunan.

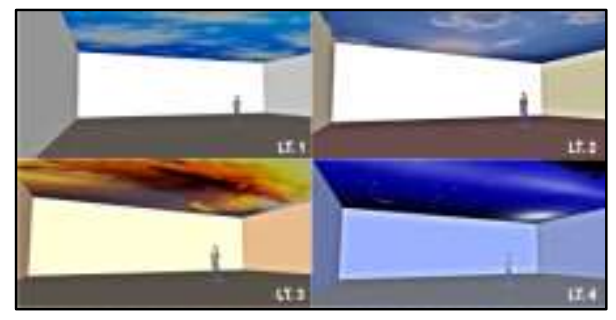

Gambar 8. Pola Plafon pada Tiap Lantai

\subsection{Analisis Sistem Struktur}

1. Tujuan: mendapatkan sistem struktur yang sesuai dengan pembebanan.

2. Dasar Pertimbangan: beban yang harus didukung, kondisi tanah, bentuk 
dan dimensi vertikal bangunan, karakter bangunan, pengaruh terhadap lingkungan sekitar.

a. Sub structure

Sub structure merupakan segala bagian bangunan yang ada di dalam / di bawah tanah, yakni pondasi tempat seluruh bangunan itu bertumpu dan tanah tempat pondasi bertumpu.

Pada bagian sub structure, pondasi yang digunakan adalah pondasi tiang pancang atas pertimbangan ketinggian bangunan yaitu 4 lantai dan 1 basement.

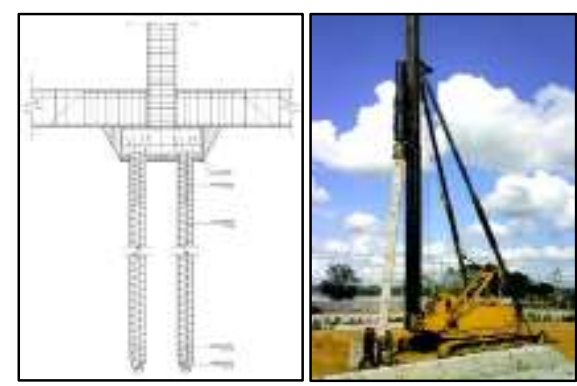

Gambar 9. Pondasi Tiang Pancang (sumber: http://belajarsipil.blogspot.com)

\section{b. Super structure}

Super structure yang digunakan adalah struktur rangka dari beton bertulang. Penggunaan kolom menggunakan bahan dari beton. Untuk material dinding menggunakan dinding batu bata untuk dinding yang menghadap ke luar bangunan dan material hebel untuk bagian dalam bangunan.

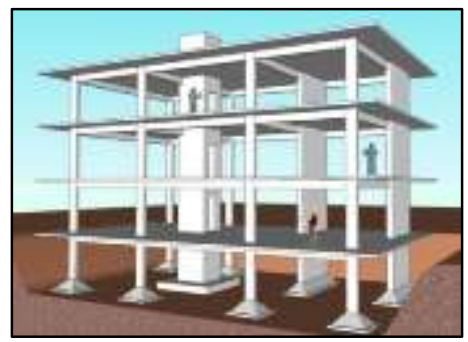

Gambar 10. Rangka Beton Bertulang

\section{c. Upper structure}

Bagian atap bangunan dipilih berdasarkan pertimbangan sebagai berikut :

1) Mendukung benangan yang lebar

2) Kekakuan dalam penyaluran beban

3) Mendukung karakteristik bangunan yang dinamis

Beberapa rangka atap yang dapat mendukung hal tersebut yaitu struktur atap baja konvensional (profil I).

Sedangkan untuk dasar pertimbangan material penutup atap adalah sebagai berikut :

1) Mendukung bentuk organik, bentuk fleksibel / lengkung

2) Dapat menahan panas matahari dan air hujan dengan baik

Dari kriteria tersebut, material penutup atap yang sesuai yaitu jenis atap tegola, yakni atap dengan bentuk hampir mirip dengan atap sirap. Atap tegola menggunakan bahan dasar dari serat fiber, yang dilapisi aspal dan ter, kemudian di atasnya dilapisi bebatuan anti panas dari meksiko dan terakhir diberi lapisan anti lumut.

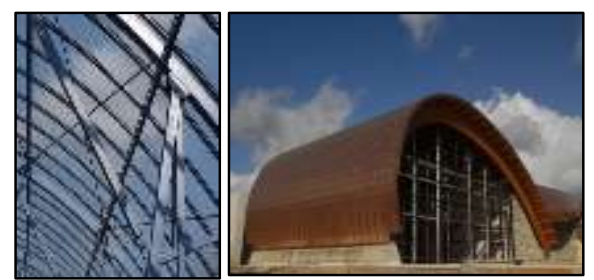

Gambar 11. Struktur Atap Tegola (sumber: www.depoklik.com)

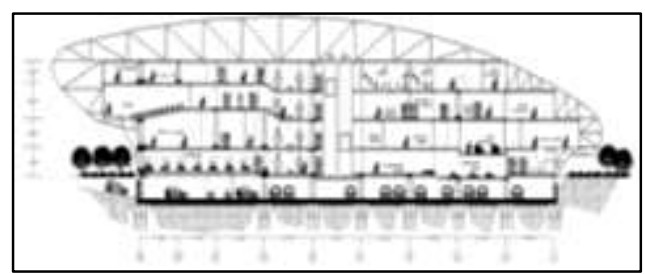

Gambar 12. Potongan Bangunan 


\section{KESIMPULAN (KONSEP DESAIN)}

Konsep rancangan wahana edukasi profesi anak mengacu pada pendekatan aspek Arsitektur Perilaku. Hal tersebut tampak pada desain rancangan interior, tampilan fasad dan bentuk bangunan. Dari hasil analisa serta hasil korelasi dari beberapa data di atas, maka diperoleh hasil berupa rancangan wahana edukasi profesi anak sebagai berikut.

$$
\begin{array}{ll}
\text { Nama Bangunan } & : \text { Wahana Edukasi } \\
& \text { Profesi Anak } \\
\text { Lokasi } & : \text { Jl. Adi Sucipto } \\
\text { Luas Lahan } & : 10.186 \mathrm{~m}^{2} \\
\text { Luas Bangunan } & : 11.573 \mathrm{~m}^{2} \\
\text { Jumlah Lantai } & : 4 \text { lantai }+1 \text { basement } \\
\text { Tinggi Bangunan } & : 23,7 \mathrm{~m} \\
\text { Daya Tampung } & : \pm 1.500 \text { orang } \\
\text { Kegiatan } & : \text { Bermain peranan } \\
& \text { profesi bagi anak }
\end{array}
$$

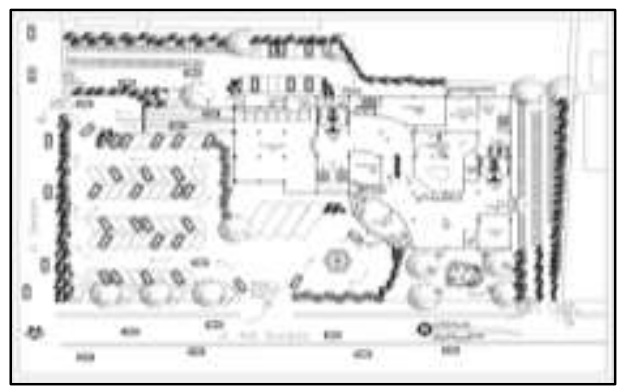

Gambar 13. Denah Lantai Dasar

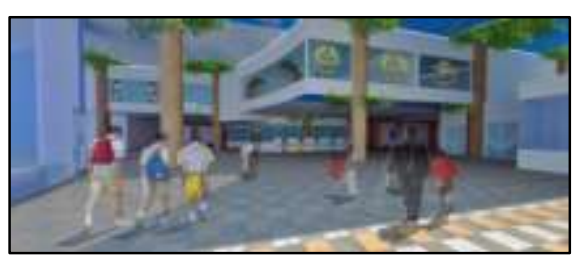

Gambar 14. Interior Bangunan

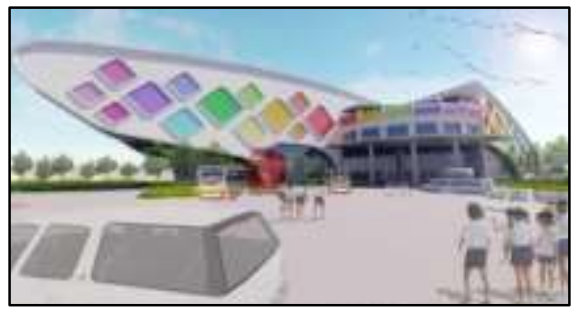

Gambar 15. Eksterior Bangunan

\section{REFERENSI}

Heimsath, Clovis AIA. 1977. Behavioral Architecture, New York, Mc.Graw-Hill Book Company

www.depoklik.com

http://belajarsipil.blogspot.com

www.rubylane.com 